\title{
The Introduction of a Great Help in College English Composition Teaching __www.pigai.org
}

\author{
Xiangfeng Guan, Qixin Liu
}

Faculty of Foreign Languages of Huaiyin Institute of Technology, Huaian, Jiangsu 223003, China guanxiangfeng01@126.com

Key words: www.pigai.org; Aeses; artificial work; correcting; English compositions

\begin{abstract}
In recent years ,more and more college English teachers and students have taken a crack at www, pigai.org either to teach or to correct English compositions .In the process ,they have found its advantages and disadvantages and the indispensable role of college English teachers to do the later correcting work. Only by the effective collaboration of Aeses and artificial work, can the correcting English compositions be more reliable and valid.
\end{abstract}

\section{Introduction}

Correcting students' compositions is a headache work for our college English teachers. But in recent years, most college English teachers in China have taken a crack at www.pigai.org to teach English compositions. On the other hand, most students also manage to use these efficient Internet resources to correct their compositions without troubling their teachers. Owing to its great convenience, some students write and rewrite their compositions of the same topic over and over again ,sometimes even for seven or more times , and correct them until they get their satisfactory marks. In fact, teaching English compositions by Internet is not a new thing. Besides www.pigai.org in China, there are three other Aeses(Automated Essay Scoring Systems) in other countries ,they are PEG ,IEA and E-rater respectively in English-speaking countries. www.pigai.org as its name indicates, it is designed specially for Chinese English teachers and students who learn English writing. In the following part, I want to talk about the advantages and disadvantages of www.pigai.org. In particular, I want to tell my experience of using www.pigai.org in my English writing classes.

\section{Www.pigai.org and its Working Principles}

Before talking about the advantages and disadvantages of www.pigai.org, we'd better first get to know what function it has and its working principles .

\subsection{Brief introduction of www.pigai.org}

www.pigai.org (which is referred to as correcting English compositions on the Internet ) is based on corpus and the cloud calculation of English compositions automatically online service system, through the calculation of the students' compositions from the standard English compositions in the corpus instantly, gives scores and comments to students' compositions and analyzes the content of their compositions. Students correct their compositions independently according to the instructions on this net. They can correct and submit their compositions for many times, until they get their satisfactory scores, which can help students improve their writing abilities. These instructions are divided into macro and micro tips, macroscopic tips give evaluations of the students' compositions as a whole, and the micro tips are for each sentence.

www.pigai.org corrects students' compositions through "relevant content", “discourse 
structures", "sentences", "collocations of set phrases", "vocabulary "and" fluency " altogether six dimensions to evaluate student's compositions comprehensively and intelligently [1] . On the other hand, it also provides teachers and students with functions for comments on each sentence, each paragraph, students' mutual comments and "BBS", etc .On the basis of intelligent evaluation, it can also provide teachers and students with artificial evaluation to ensure the accuracy of evaluation . Evaluation for each sentence includes "sentence errors" , "spelling mistakes"," warning for suspected chinglish ", "learning tips", "tips to correct", " phrases for high marks", "tips for collocations " and "syntax checking', etc. After the system has completed the evaluation, students can perfect their compositions according to the system tips until they are satisfied, and then they accept "teachers' comments " and "classmates' comments ". Teachers' comments give students great help to their writing. As for the arranged functions (particularly in terms of web interface design), they are more suitable for Chinese students' learning characteristics. After students have submitted their compositions, www.pigai.org begins to comment on students compositions according to "each "sentence", and "gives scores " (which include scores for "overall score", "vocabulary score",structure score", "content score" and "its comments "as well .

\subsection{Working principles}

www.pigai.org regards students' compositions as a learner corpora, the scores of each composition consists of 192 subdimensions. By the contrast of students' compositions and standard English compositions in the corpus, the distance measured will be transformed into students compositions' scores, evaluation and feedback. The whole process of composition correcting is just as a teacher's correcting of students' compositions from multiple dimensions. Moreover, it gives an overall feedback and make comments on each sentence, points out the mistakes existed in each sentence. At the same time, it is based on the system Web2.0, which supports the teacher to correct students' compositions online. Teachers can give further corrections on the basis of the system correcting tips.

\section{Advantages of www.pigai.org}

\subsection{High working efficiency}

As is known to all, Chinese college English teachers' teaching task is very

heavy. In recent years, due to the expansion of the enrollment of college students, the number of students in each class is getting more and more,sometimes even up to more than 100 . it is common that each college English teacher usually teaches three or four classes. When they assign one composition to all his students, it usually takes them a week or two to correct these compositions in their spare time. When they give their feedback to their students, the students have almost forgotten their compositions, and also lost their interest, let alone correct them according to their teacher's instructions. As time goes on, teachers and students will lose their interest and enthusiasm in English compositions writing, who will just regard it as the obliged task to accomplish gradually. In contrast, correcting English composition automatically online has increased its efficiency greatly, estimated about one hundred times faster .which is regarded as one of the biggest advantages .Students submit their English compositions to the net ,they will soon be able to see the score and comments of their compositions by the feedback on the net instantly, which is expected by the students ,hence arousing their interest in English composition writing and improving their writing abilities .

\subsection{Strong objectivity and fairness}

Quality of an English composition is usually judged by the language, content and writing skills and other skills used in the composition from comprehensive perspectives .But traditionally, English teachers correct students English compositions with their own preferences, either preference for comprehensive use of English language, fluency or content. When they correct students' 
compositions, they will give high marks in their favor. But when they correct compositions full of mistakes and not suitable for their preference, they will give low marks, which has lost its objectivity and fairness .On the opposite, when www.pigai.org corrects students' English compositions, it will evaluate them automatically according to certain criteria, it keeps its objectivity and fairness, which will not hurt students' feelings and enthusiasm in English composition writing .

\subsection{Comprehensive and detailed evaluation comments}

Due to the large number of students and heavy burden of English composition correcting, most college English teachers in China don't have enough time and energy to correct so many English compositions , and they can't correct students' English compositions comprehensively and in a detailed way. But for the automatic online correcting based on the standard English compositions in the corpus, www.pigai.org will compare the students' English compositions with English compositions in the corpus and will find, point out and correct language mistakes of grammar and pragmatics which don't conform with the rules of English language. It will also evaluate the content and organizational structures of the composition etc. From the comments, students can learn whether their spelling of English words, collocation of phrases ,each sentence, logical relationship between sentences and even punctuation marks are right or not . Besides, they can also know whether their composition is relevant to the title and the structure is reasonable or not. Students can know their compositions comprehensively and correct them in time with such detailed information ,thus improve their English application abilities.

\section{Disadvantages of www.pigai.org}

\section{1 Over mechanical and blind in its judgment}

Since it is based on English compositions stored in the corpus to correct students' compositions automatically online, after all, www.pigai.org is machine operation, and just as computer processing other information, it operates on the input mechanical program. When it meets special situations and new problems, it cannot work creatively and flexibly[2]. For example, it might overlook students' creative thinking in their compositions and fix on one mistake, which may do harm to students' creativity .In addition, it also contains machine blind characteristics, for example, it can't change its scoring criteria according to the easiness and difficulty of the composition .

\subsection{Errors existed in its analyses}

In the process of net correcting, careful teachers and students will find that www.pigai.org often makes wrong analyses for the wrong usages of English language[3]. The example is as follows:

by his ok with me, i know i was good If you work hard you will success.

www.pigai.org only points out the mistakes of the capital letter in the sentence not capitalized,wrong use of punctuation marks and low frequency warning of his ok with me ,but for the word in the sentence ,such as "i" and wrong collocation of "will success", it has not mentioned these mistakes .

\subsection{Teachers will rely too much on online correcting}

Correcting English compositions online is no doubt fast and convenient, which will render teachers to rely entirely on the network correcting and neglect their role of correcting [4], so we strongly recommend teachers spare some time to do the later correcting work for the sake of students .

3.4 The reliability and validity still needs to be improved

Automatic grading of English compositions is a very complicated technology ,only by 
reasonable use of multi-disciplinary technology, in combination with the language test theory, can it achieve the ideal effect [5]. As college English teachers, we expect more accurate and advanced software will come into being in the near future .

\section{Conclusion}

In brief ,www.pigai.org is machine operation, and just as computer processing other information, it operates on the input mechanical program . When it meets special situations and new problems, it cannot work creatively and flexibly. So in this case ,our college English teachers should do the later part of correcting work for the sake of our students .Hence, improving their English composition writing abilities comprehensively .

\section{Acknowledgment}

Thanks are due to my colleagues for their assistance in writing this essay .

\section{References}

1. English Writing Teaching in China Intelligent Tutor System : Achievements and Challenges . Yan Jiang, Wulin Ma .Course and Teaching[J]. No.7 ,2013: 77-78 .

2. Evaluation for English Composition Correcting Online Based on the Corpus .Jingling Liu .China Education Innovation Herald [J]. No.10,2013:35-36 .

3. The Introduction and Enlightenment of Intelligent Evaluation System for English Compositions.Fang Wu .Education Exploring[J] .No.11,2012:189-190.

4. Where Is the Way to College English Teaching Reform in China ? Mingqian Deng ,Liwei Zhang. World Education Information [J] .No.8,2011:25-26 .

5. Research on Online Automatic Correction System Application in College English Writing Teaching . Xiaoling Shi . Modern Education Technology [J] . No.10 ,2012 : 67-68 . 